\title{
Integration of water transport pathways in a maple tree: responses of sap flow to branch severing
}

\author{
Nadezhda NADEZHDINA* \\ Institute of Forest Botany, Mendel University of Agriculture and Forestry, Zemĕdĕlská 3, 61300 Brno, Czech Republic
}

(Received 22 January 2009; accepted 16 June 2009)

\author{
Keywords: \\ Acer platanoides / \\ flux distribution / \\ heat field deformation method / \\ integrated pipes / \\ multi-point sensors / \\ stem xylem functional structure
}

\begin{abstract}
- It has been known for a long time that sectored and integrated patterns of vascular systems exist in different species and even within the same tree, depending on its age and history. However, very few publications consider the topology of the vascular pathways between roots and branches.

- Some results on this important aspect of the vascular system are presented in this paper. They have been obtained with adult maple trees by directly studying the water movement in the stem and root xylem with the heat field deformation (HFD) method for sap flow measurements.

- Multi-point HFD sensors were installed at different heights of a Norway maple tree (Acer platanoides L.) along its stem axis. Single-point HFD sensors were installed in three small lateral roots of another sample maple. Experimental treatments (branch severing) triggered changes in sap movement in the stem and root sapwood.

- The sample trees belong to the group with an integrated transport system ("integrated pipes"), sharing stem space on both sides of the tree to supply two large parts of the crown with water from each root sector. Nevertheless, conducting pathways had their autonomy for axial transport and the pipe model theory describes the vascular system of the studied trees well. Thus, the integration of axial transport in the stem xylem should presumably occur through the cross-grained network of axial vessels.
\end{abstract}

Résumé - Intégration des voies de transport de l'eau dans un érable : réponses du flux de sève à une ablation de branche.

- Il est connu depuis longtemps que des modèles sectorisés et intégrés de système vasculaire coexistent chez différentes espèces et même dans un arbre unique, en fonction de son âge et de l'histoire. Cependant, très peu de publications ont examiné la topologie du parcours vasculaire entre les racines et les branches.

- Quelques résultats sur cet aspect important du système vasculaire sont présentés ici. Ils ont été obtenus avec des érables adultes en étudiant directement le mouvement de l'eau dans le xylème de la tige et de la racine avec la méthode de déformation du champ de chaleur (HFD) pour mesurer le flux de sève.

- Des capteurs HFD-multi-points ont été installés à différentes hauteurs dans un érable plane (Acer platanoïdes L.) le long de la tige. Des capteurs HFD-simple-point ont été installés dans trois petites racines latérales d'un autre érable. Des traitements expérimentaux (ablation de branche) ont déclenché des changements dans la circulation de la sève dans l'aubier de la tige et de la racine.

- Les arbres échantillonnés présentent un système vasculaire intégré («tuyaux intégrés »), avec un tronc partagé en deux secteurs alimentant les deux grandes parties de la couronne avec de l'eau à partir des racines de chaque secteur. Néanmoins, les parcours conducteurs de la sève ont leur autonomie pour le transport axial et la théorie du pipe model décrit bien le système vasculaire des arbres étudiés. L'intégration du transport axial dans le xylème de la tige se fait probablement par l'intermédiaire d'un réseau interconnecté de vaisseaux axiaux.

\footnotetext{
*Corresponding author: nadezdan@mendelu.cz
} 


\section{INTRODUCTION}

Study of the structure and function of tree xylem systems is a crucial aspect of ecophysiology. Using the example of Pinus sylvestris, Kaipiainen and Sofronova (2003) concluded that the transport network and its conducting capacity are essential for the coordination of tree growth and development. Orians and Jones (2001) considered vascular architecture as a key determinant of within-plant heterogeneity, which is ecologically important for plant-consumer interactions. However, hydraulic interactions between different sinks and sources through conducting pathways in tree stem xylem have not received enough attention. Boyer (1985) noted that water transport through the whole plant is complicated by several types of flows occurring simultaneously, including those for absorption and transpiration and the storage fluxes for growth and hydrationdehydration. He emphasized that water-conducting pathways in trees are so complex that they could be considered as a "black box", which has forced researchers to measure flows and their driving forces without knowing the precise nature of the flow path.

Although upwards water movement in the tree stem is quite comparable in conifers and dicotyledons and functionally equivalent in the monocotyledons, as Zimmermann (1983) noted, it has long been suggested that species differ in how sectored they are and that they could be divided into two big groups: sectored and integrated. The vasculature of monocots (grasses and palms) is more integrated than that of dicots (Watson and Casper, 1984). Among trees, ring-porous species and some conifers tend to be more sectored, and diffuseporous species are regarded as more integrated. Some authors have found sectored flow to rely on direct connections between a certain part of the root system and only part of the foliage, usually situated on the same side of the stem (Larson et al., 1994; Matthes et al., 2002; Nadezhdina et al., 2001). Lanner (2002) includes a sectored vascular system in a set of unique characteristics of trees contributing to their longevity. However, many other studies (Kaipiainen and Hari, 1985; MacKay and Weatherly, 1973; Roach, 1939; Vité and Rudinsky, 1959), as well as our unpublished data with staining experiments in apple, lime and maple trees, illustrate that interactions between conducting tissues in the stem xylem increase toward the top of the tree. Thus, as Watson and Casper (1984) proposed, "plants rather exist somewhere on a continuum from total integration to highly localized sectorialization".

Among the several models describing water transport in the xylem, two extremes are often considered: a fully-coupled three-resistor model (Huber, 1928; Van den Honert, 1948), which allows separate sources to share a common sink, and an uncoupled pipe model (Shinozaki et al., 1964a; 1964b), in which separate sinks and sources are assumed to be connected by independent pipes. Results of some studies are consistent with the pipe model theory (Infante et al., 2001; Waring et al., 1977, West et al., 1999) and others with the fully-coupled model (Pataki et al., 1998; Tyree and Ewers, 1991). The variable results of some studies (Hubbard et al., 1999; Pepin et al., 2002; Whitehead et al., 1996) suggest partial autonomy of xylem water pathways. Data by Schulte and Brooks (2003) and Brooks et al. (2003) demonstrate that hydraulic systems within branches are relatively unconnected. Fujii et al. (2001) found the branching of vessels in a diffuse-porous wood of Machilus thunbergii. So, the problem of the topology of the vascular connections between roots and branches is quite difficult, especially for integrated species. Integration within the stem xylem may occur not only through intervessel pits of adjusted vessels (Orians et al., 2005), but also due to crossgraining of xylem vessels, which deviate from their axial path (Kitin, 2004; Zimmermann, 1983). For integrated topology it is still not clear which kind of integration and under which circumferences prevails: is it integration of independent pipes anatomically sharing space in the stem xylem due to the crossgrained network of xylem vessels or is it integration of pipes interconnected through pit membranes?

A number of methods have been used for both validation of the models and study of tree vascular architecture. Sap flow techniques may be one of the most useful emerging tools for examining tree xylem structure, because they can be used to directly monitor the water movement in conducting elements. Sap flux was monitored, for example, by Schulte and Brooks (2003) and Brooks et al. (2003) in their studies. But measured fluxes were used only to show that the transpiration of treated branches was really reduced by bagging and shading. The radial variability in sap fluxes in the stem xylem of trees has been reported in numerous studies (Luttschwager and Remus, 2007; Nadezhdina et al., 2002; Saveyn et al., 2008; Wullschleger and King, 2000). However, no studies have ever linked whole-plant architecture and sap flow in different parts of a tree and related hydraulic interactions of stem xylem layers connecting different below- and above-ground tree sectors. We found only a few models trying to link tree architecture with sap flow and other physiological processes at the wholeplant level (Alarcon et al., 2003; Kurth and Lanwert, 1995). The xylem network topology has been considered recently for the first time for the modeling of water transport in the xylem as a system-level process (Loepfe et al., 2007). Cruiziat et al. (2002) emphasized that a spatial mapping of the real fluxes within the various parts of a tree is necessary for a better understanding of the water relations of a tree.

Sap flow measurements with a high time resolution, combined with experimental manipulations, could be applied for studying tree hydraulic architecture in situ. The heat field deformation (HFD) method (Nadezhdina et al., 1998) is very helpful in this respect, especially because it allows one to carry out sap flow measurements at different depths along a xylem radius with thin sensors around a common linear heater. The fast-responding and highly sensitive HFD method can record all flow changes within xylem pathways, which was demonstrated during experimental treatments of stems, roots and branches (Nadezhdina and Cermak, 2000a; 2000b; Nadezhdina et al., 2004; Stokes et al., 2000).

In this study, maple tree (Acer platanoides L.) was chosen as a representative example of diffuse-porous trees known as integrated (Zanne et al., 2006). Experiments were designed with a different approach than those used earlier for studies of tree vascular connections: application of dye (Larson et al., 1994; Roach, 1939; Vité and Rudinsky, 1959) or isotopes of 

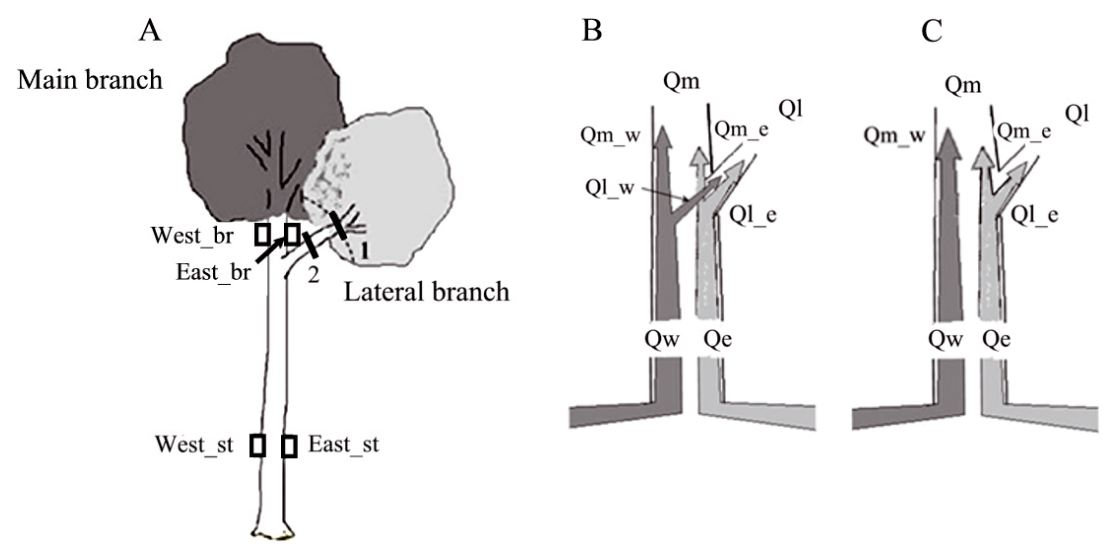

Figure 1. (A): Scheme of experimental treatments and positioning of the HFD sensors on the main experimental maple tree (Exp. 1). The lateral branch on the East side was subsequently cut twice. After the first cut a small part of the crown (indicated by the dashed line) was left and then the rest of the crown was removed with the second cut. Schemes of different possible topologies of the vascular connection between roots and branches in the stem: integrated (B) and sectored (C). Flows from root sectors on each side of the stem $\left(Q_{\mathrm{w}}\right.$ and $\left.Q_{\mathrm{e}}\right)$ are apportioned to two big branches $\left(Q_{\mathrm{m}}\right.$ and $\left.Q_{1}\right)$. Flow from the eastern stem side supplies the main $\left(Q_{\mathrm{m} \_\mathrm{e}}\right)$ and the lateral $\left(Q_{\mathrm{l}_{\_\mathrm{e}}}\right)$ branches. Flow from the western side supplies either both branches $\left(Q_{\mathrm{m}_{-} w}\right.$ and $\left.Q_{\mathrm{l}_{\_} \mathrm{w}}\right)$ in the case of integrated tree architecture $(\mathrm{B})$ or only the main branch in a sectored tree $(\mathrm{C})$.

mineral nutrients (Orians et al. 2004), measurements of branch hydraulic properties (Zanne et al., 2006), X-ray computed microtomography (Steppe et al., 2004) or complex microscopic analysis (Kitin et al., 2004). It was hypothesized that measurements of radial sap flow patterns in the stem xylem and their changes due to severing treatments would help to recognize axial water pathways leading from the opposite roots through the stem xylem to different fractions of the crown. Sink severing was assumed to be a more suitable treatment than source severing because it does not introduce worsening of tree water supply. Earlier measurements of sap flow around tree bases, eventually combined with opening of root systems with an air-spade, had shown that the conducting xylem at the stem base is very sectored and connected to roots from the sector nearest to the stem sector (Cermak and Kucera, 1990; Nadezhdina and Cermak, 2003). Thus, incoming fluxes on the stem base sides can be assumed to be fully separated from opposite roots. The cross-grained network of conducting vessels leads to their radial and especially tangential drift from the axial tree line (Kitin, 2004; Zimmermann, 1983), and thus to integration within the stem xylem, which increases with tree height. Integration of the axial pipes via intervessel pits was ignored, supposing that it should be predominantly responsible for horizontal transport (Kitin et al., 2004) and thus for water redistribution within the tree xylem, with its importance increasing under severe environmental conditions. Details of the experiments supporting the hypothesis of the study are described in the following section.

\section{MATERIALS AND METHODS}

\subsection{Site description and environmental measurements}

The experiment was conducted in August 1999 (DOY 211-220) in the Sobesice forest district (a suburb of the city of Brno, Czech
Republic) at an altitude of $360 \mathrm{~m}$. Soils are illimerized on weathered granodiorite with a cover of loess to a depth of 30-40 cm. The mean annual temperature is $7.8^{\circ} \mathrm{C}$ and the mean annual precipitation $580 \mathrm{~mm}$, of which $360 \mathrm{~mm}$ fall during the growing season (Vasicek, 1984). Air temperature and global radiation were monitored at 1- and 15-min intervals (Unilog meteostation, Brno, Czech Republic) in an open place close to the sample tree at a height of $5 \mathrm{~m}$.

\subsection{Experimental design}

Sap flow responses on branch severing were studied on two specimens of a diffuse-porous Norway maple (Acer platanoides L.), and for each tree a special experimental design was applied. During the main experiment (Exp. 1) responses of sap flow on branch severing were examined in the stem xylem by the multi-point HFD sensors in order to follow direct changes in sap flow radial profiles after branch cutting. An additional auxiliary experiment (Exp. 2) was carried out on another sample maple in order to verify the connection of a severed branch even with small roots around a tree.

\subsubsection{Experiment 1: responses of stem xylem to branch severing}

A sample tree was selected with two large branches of rather similar size. It had a DBH of $27.5 \mathrm{~cm}$. Its somewhat larger main branch (20 $\mathrm{cm}$ in diameter) continued the stem axis, whereas the smaller lateral branch $(18 \mathrm{~cm}$ in diameter) was pushed aside into an eastern direction (Fig. 1A). Two pairs of HFD sensors were installed at breast height from the opposite sides of the stem (marked East_st and West_st) and just below the crown of the main branch (marked East_br and West_br) at a height of $11 \mathrm{~m}$. After several days of sap flow measurements the lateral branch was severed at midday (August 1) when transpiration was highest and rather stable; thus, higher responses could be expected. The branch was cut twice subsequently with a time lag of around $2 \mathrm{~h}$ (see Fig. 1A): cut_1 was made at 11:54 
A

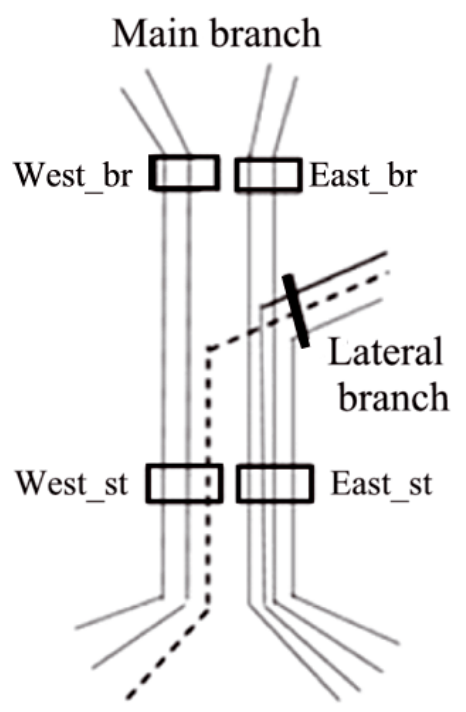

B

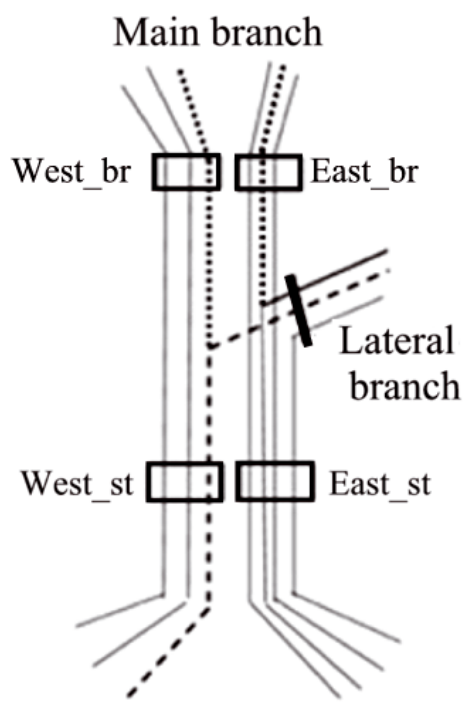

Figure 2. Hypothesized schemes of an integrated topology of vascular connection within the stem xylem and installation of sap flow sensors to verify if integrated pipes were independent (A) or interconnected (B).

and cut_2 - at 13:47. The main part (around 90\%) of the wellilluminated foliage from this branch was removed by the first cut, whereas the remaining around $10 \%$ of the foliage (always shaded by the upper foliage of the same branch before cut_1) was removed by the second cut. Only a small fraction of total branch leaf area was left after the first cut in order to check the sensitivity of the method and to examine the contribution of such a small fraction of shaded foliage to overall flow in a tree stem.

Substantial responses on branch severing were expected at the stem sensor on the eastern tree side where pathways from roots to both branches evidently passed (Figs. 1B and 1C). Either no response in the case of sectored tree architecture (see Fig. 1C) or a reduced response in the case of integrated topology (see Fig. 1B) was expected at the western stem sensor.

The branch sensors were installed within the same vertical plane with the stem sensors to check the independence of integrated vascular connections of water pathways in the sample tree (Figs. 2A and $2 \mathrm{~B}$ ). Assuming that the directions of fluxes are vertical, flow in the main branch before cutting the lateral branch should be equal to the flow in the stem after severing treatment. Bearing in mind that the cut was performed at midday, when sunlight already came from the south, a change in illumination of the main branch due to the cut should not be important because the lateral branch was east-oriented and lower than the main branch. Thus, in the case of independent water pathways (see Fig. 2A) in the stem xylem, no changes should be expected in the main branch flux in contrast with a large decrease in fluxes at the stem base after severing of the lateral branch. A partial increase in fluxes was expected in the main branch if both branches were interconnected and shared pipes at the stem base (see Fig. 2B).

\subsubsection{Experiment 2: responses of root xylem to branch severing}

Another specimen of Acer platanoides was used for studying the reaction of sap flow in several superficial roots to branch removal.
The second Norway maple with a DBH of $23 \mathrm{~cm}$ was growing several meters from our first sample tree. This time, three single-point sensors were installed in small surface roots differently oriented (South, East and North). Root diameters were $2.8 \mathrm{~mm}, 3 \mathrm{~mm}$ and $4.6 \mathrm{~mm}$ for the southern, eastern and northern roots, respectively. A large SW-oriented branch was cut in the middle of the day (Fig. 8A).

\subsection{Determination of fluxes through stem and branches}

The tree base was considered as a zone with "incoming" source fluxes and "outgoing" sink fluxes in balance. Stem fluxes coming from the corresponding root sector, $Q_{\mathrm{w}}$ and $Q_{\mathrm{e}}$, will be redistributed further between both branches: $Q_{\mathrm{m}_{-} \mathrm{e}}$ and $Q_{\mathrm{l}_{\_} \mathrm{e}}$ are fluxes through the eastern part of the stem to the main and lateral branches and $Q_{\mathrm{m}_{-} w}$ and $Q_{l_{\text {lw }}}$ are fluxes through the western part of the stem to the main and lateral branches, respectively (see Fig. 1).

It is evident that the fluxes in the stem remaining after severing of the lateral branch would be only those fractions of the original total which connected each stem side with the main branch. Therefore, fractions of fluxes in different sapwood layers connecting each side of the stem to the lateral branch $\left(Q_{l_{-} w}\right.$ and $\left.Q_{l_{\_} \text {e }}\right)$ can be calculated by subtracting the remaining fluxes after branch cutting from fluxes measured before at the stem base. Fluxes moving to branches, $Q_{\mathrm{m}}$ and $Q_{\mathrm{l}}$, could be calculated then from flux fractions measured at opposite stem sides.

\subsection{Sap flow measurements by the heat field deformation method}

Sap flow was measured by the heat field deformation (HFD) method (Nadezhdina et al., 1998; 2008) by applying multi-point sensors. Sap flux densities were determined as a function of the ratio of two temperature differences recorded in the axial (symmetrical $\mathrm{d} T_{\text {sym }}$ ) 
and tangential (asymmetrical $\mathrm{d} T_{\text {as }}$ ) directions from the heater in a common chosen "tangential section" of a stem perpendicular to the xylem radius, $R_{\text {xyl }}$, which is equal to the stem radius at the measured place without bark. Both the heater and the differential thermocouples were put into stainless steel hypodermic needles $(1.5 \mathrm{~mm}$ external diameter). Each needle of the multi-point sensor contained six thermocouples $10 \mathrm{~mm}$ apart. The first measuring point was $4 \mathrm{~mm}$ below the cambium. So, we measured temperature gradients around the heater at six depths $(4,14,24,34,44$ and $54 \mathrm{~mm}$ below the cambium, respectively) in six different "tangential sections" along the xylem radius. The heat field in each measured section was deformed according to flow rates in the corresponding xylem layer. Data were recorded at 1-min intervals by Unilog dataloggers (Midi-12, EMS Brno, Czech Republic).

Sap flux densities (SFD) calculated from the measured temperature gradients (Nadezhdina et al., 2008) show only the situation at a certain stem sector, which could vary in circumferential direction. Thus, they should be used only qualitatively as a tool for the topological study of the vascular system of a tree. However, in order to verify the independence of water pathways at the stem base directed to the main and the lateral branches from different root sectors, flows at the base and main branch levels were scaled up and compared before and after severing the lateral branch. Flow in the main branch should not change dramatically after severing the lateral branch, but flow at the tree base should decrease approximately to the level of flow in the main branch. In order to integrate sap flow over the whole sapwood depth, sap flux densities measured at both sides of the stem or the main branch were averaged for each measured depth and then mean SFD was multiplied by the corresponding area of a sapwood ring where the measuring point was centered. Sap flow for the stem or branch level was summarized from flows calculated for separate sapwood rings.

\section{RESULTS}

The days of the experiments showed rather similar weather conditions: all were warm and slightly cloudy. No rain events occurred during this period. Sap flow dynamics in all measured parts of the maple tree (the experiment 1) were synchronous with the dynamics of global radiation. The stem sap fluxes at breast height decreased immediately after severing the lateral branch (Figs. 3 and 4), clearly separating fractions of fluxes at each side of the stem associated with the lateral and main branches. Fluxes dramatically decreased in almost all xylem layers at both sides of the maple stem after the first cut. This decrease was more significant at the eastern stem side. The fluxes originally directed to the lateral branch were observed in the middle xylem layers at the eastern stem side and they were shifted to the inner xylem in the western stem. The second cut caused a further decrease in fluxes and their redistribution in xylem layers at both stem sides, but responses to the second cut at both sides of the stem were not substantial when compared with the first one. The decrease in fluxes during the second cut was uniform over the whole sapwood at the eastern side and took place only in the inner xylem of the western side of the stem. Fluxes to the rest of foliage of the lateral branch were very low and could be neglected for further analyses: they were much lower than the changes in fluxes due to the time lag between the two cuts (see Figs. 3 and 4).
Neither abrupt changes in fluxes nor their redistribution between xylem layers after both cuts of the lateral branch were recorded by sensors just below the crown of the main branch, where only a gradual daily variation in fluxes due to radiation was observed (see Fig. 3). Slightly lower fluxes observed after the second cut in xylem layers of the main branch at both sides were caused by the time lag of $2 \mathrm{~h}$ between the beginning and the end of the experiment (see Fig. 4).

We see that mean stem fluxes followed a rather symmetrical bell-shaped curve, although different sinks and sources utilized the stem xylem quite asymmetrically (Fig. 5). Cutting a large part of the foliage disturbs the symmetry of mean stem fluxes. The new sap flow profiles in the stem xylem originating from the severing treatment persisted for a long time (data not shown). Total flow per tree at the tree base was $8.7 \mathrm{~kg} \mathrm{~h}^{-1}$ before the treatment, but it decreased to $4.5 \mathrm{~kg} \mathrm{~h}^{-1}$ just afterwards. Total flow per main branch was $4.7 \mathrm{~kg} \mathrm{~h}^{-1}$ before the treatment and $4.6 \mathrm{~kg} \mathrm{~h}^{-1}$ afterwards.

Examination of incoming flux portioning in the stem xylem indicates that fluxes originating from the eastern root sector moved very asymmetrically to the branches, with the exception of the middle part of the stem sapwood, which supplied both branches equally (Fig. 6). Most of the water (up to 80\%) moved through the inner and the outer sapwood to the main branch and the small remaining amount of the water moved to the lateral branch through the same parts of the stem sapwood. The western root sector also supplied water to both branches very asymmetrically: substantial amounts of water moved to the main branch mostly through the outer stem xylem (up to $100 \%$ in the outermost xylem), while only the inner xylem connected those roots with the lateral branch (up to 40\%). When the flux fractions from different root sectors were summarized (Fig. 7), a common picture of flux redistribution in the stem xylem became well visible.

Fluxes in the small roots differently oriented around the stem of the second sample maple (Exp. 2) decreased immediately after severing the large south-west branch (Fig. 8). The biggest decrease was detected in the southern root, which was closer to the cut branch than other examined roots. Branch severing caused not only abrupt immediate flux changes in all roots but it also changed daily flux dynamics in them.

\section{DISCUSSION}

The severing treatment as reflected by sap flow measurements with high time resolution (see Fig. 3) allowed us to distinguish how fluxes "incoming" from opposite root sectors were apportioned in the stem xylem at BH between two branches (see Fig. 5). Fluxes spread and overlapped gradually with tree height, and the conducting xylem just below the crown of each branch was evidently connected with all roots. This fact was confirmed later in an additional experiment with another maple tree where sap flow was measured directly on roots (Exp. 2). The sensors in all roots detected an immediate response on branch severing with different percentages of flux decrease (see Fig. 8B). This clearly reflects the different participation of the studied roots in water supply of the cut 


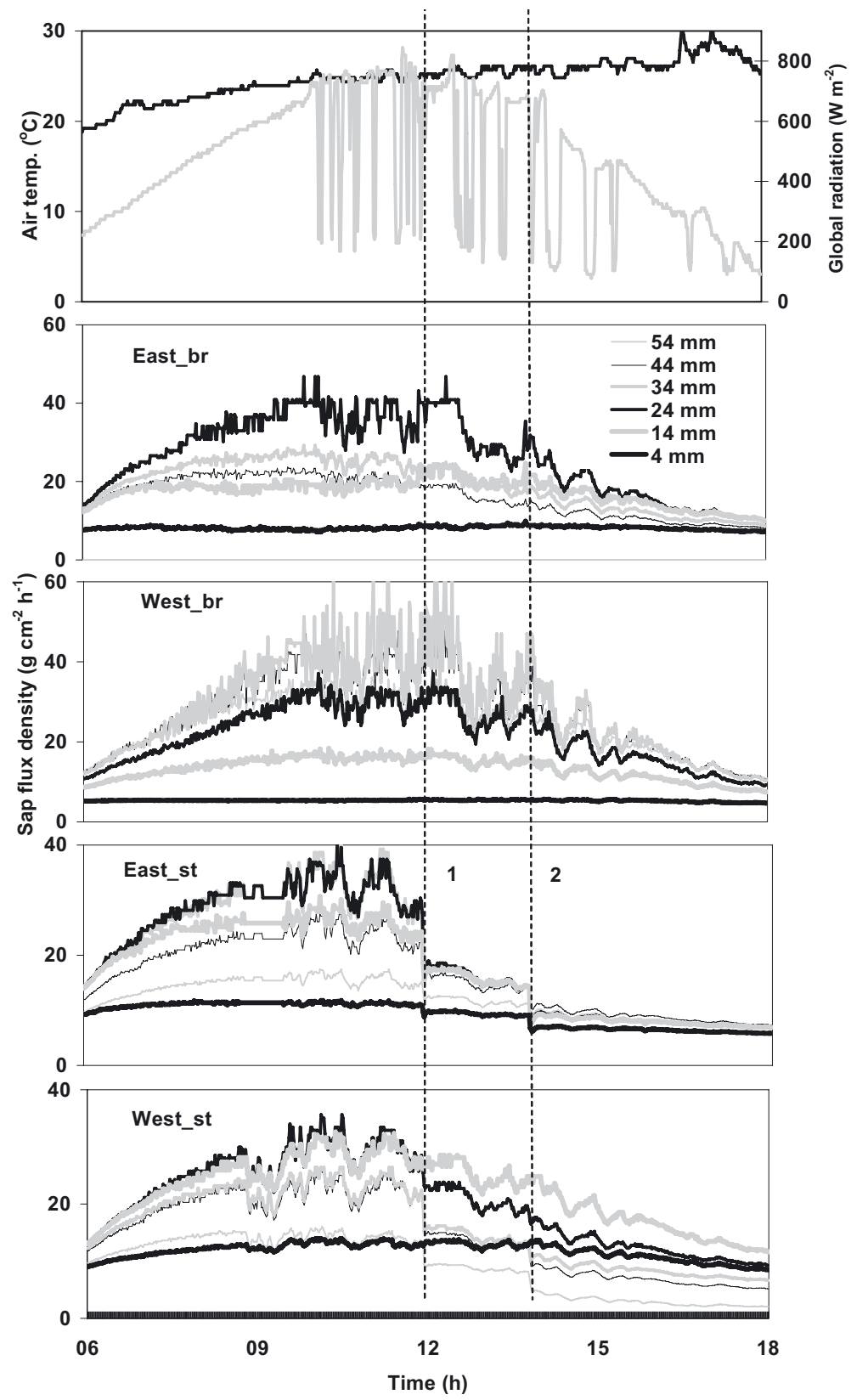

Figure 3. Dynamics of sap flux densities measured by the multi-point HFD sensors in the control lime tree (Tilia, South) and in the sample maple tree at different sides and heights (East_st and West_st - at breast height and East_br and West_br - just below the crown of the main branch) during the first severing experiment. Numbers denote the depth of the measuring points below the cambium (mm). Vertical lines mark the two moments of severing the lateral branch. Data with a 1-min recording interval are presented.

branch. Spreading of fluxes with tree height may occur due to tangential drift of conducting vessels around the stem axis, which has been shown as a general occurrence (Kitin et al., 2004; Zimmermann, 1983). The way for the tangential drift is shorter in the inner stem xylem, which evidently can explain the fact that responses on branch severing were detected only in the inner xylem of the opposite stem side (see Fig. 6). It is also interesting to note here the very different percentage of flux fractioning to both branches in the xylem from the opposite stem sides.
The absence of flux responses in both sides of the main branch (see Figs. 3 and 4) on the lateral branch severing indicates a lack of direct interconnections between both branches. The two subsequent cuts of the same branch made it possible to distinguish the higher fluxes in the stem xylem to the better illuminated higher part of the branch (severed first) from the fluxes to the shaded lower part of the branch severed with a certain delay. Flow in the main branch was about $54 \%$ of the total flow in the tree before branch severing and close to the total after the treatment. The latter could be considered as 

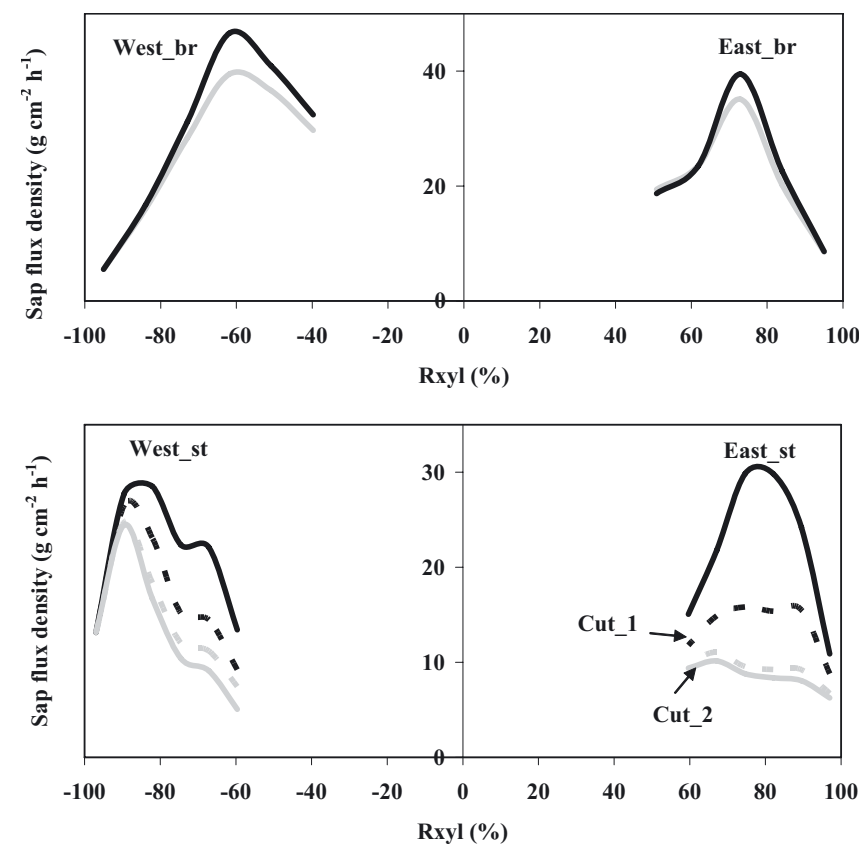

Figure 4. Upper panels: radial pattern of sap flux densities measured at two opposite sides of the main branch before (black lines) and after (grey lines) the two cuts. Due to high variability in data measured just below the crown, they were averaged for 15-min intervals before cutting and after the second cut. Lower panels: radial pattern of sap flux densities measured on the eastern and the western sides of the maple stem 1 min before cut_1 (black solid line - 11.53) and cut_2 (gray dashed line -13.47), as well as 2 min after the second cut (black dashed line corresponds to the time 11.56 after cut_1 and grey solid line corresponds to the time 13.50 after cut_2). Differences between black and grey dashed lines demonstrate changes in radial pattern due to the time lag between the two cuts (11.54-13.48). See also Figure 4 for details where dynamics of SFD are presented during the day of the main cutting experiment. Negative $X$-axes were used for the western side in order to illustrate its opposite direction better compared with the eastern side and the position of the pith in the middle. Symbols indicating measured points along radial profiles were omitted for clarity and better visualization of radial pattern changes. $R_{\mathrm{xyl}}$ means stem radius in a measured place without bark thickness.

the second confirmation of independence of the axial pipes directed to both branches.

When looking at the same stem xylem from the point of view of "outgoing" flows (Fig. 7), we can see that the outer layers were obviously used for water transport to the main branch. This could be explained by peculiarities of the architecture of the particular sample tree, where the main branch extended the main stem (see Fig. 1A). Our observations confirm one of the major (Huber, 1928) contributions to plant hydraulic architecture, namely that the leader is better supplied by xylem transport than the laterals.

The results show that the experimental trees belong to a group of diffuse-porous species with "integrated pipes" sharing stem space in order to reach two large parts of the crown from all root sectors. Zimmermann (1983) underlined

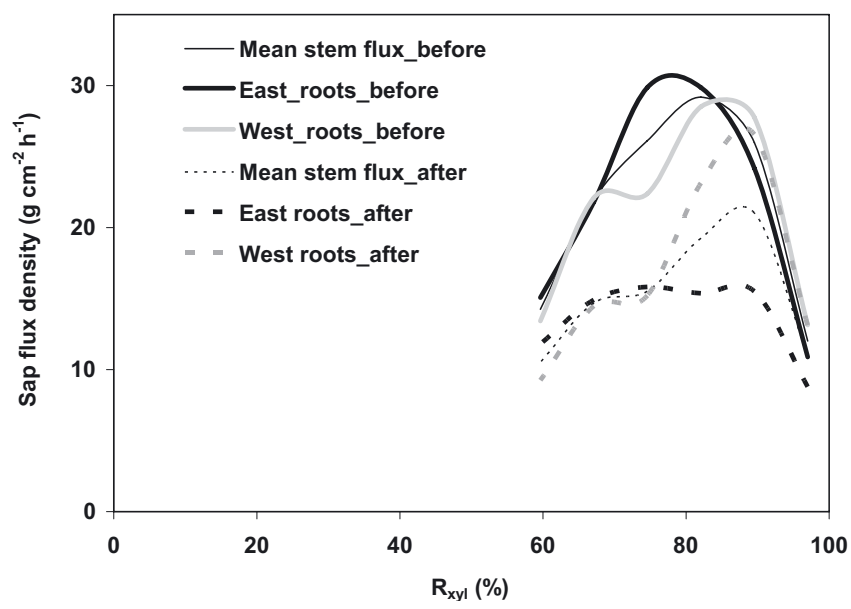

Figure 5. Radial patterns of sap flux densities, demonstrating partitioning in the stem of water taken up from eastern (thick black lines) and western (thick grey lines) roots before (full lines) and after (dashed lines) the severing of the lateral branch. Thin black lines characterize mean profiles of water uptake before and after the treatment. See also Figure 4 for details. $R_{\text {xyl }}$ means stem radius in a measured place without bark thickness.

the physiological significance of such a complicated layout of vessels in plants, calling it "a marvelous safety feature of the xylem". We also found that conducting pipes had their autonomy for axial transport. Cutting was done not on the main stem, but far from it on the lateral branch. A very clear and abrupt response was recorded in the lower stem at $\mathrm{BH}$ and not in the upper stem below the main branch. This is an indication that the severed branch was connected with the stem xylem at $\mathrm{BH}$, but not with the main branch. Moreover, the main branch did not use free pipes of the stem. Redistribution of fluxes within the stem xylem at breast height caused by branch severing persisted until the end of the growing season. The cut "opened" pipes, where water was then no longer under tension, lost their functionality and conductivity before being included in a "closed" system again. Will pipes be "repaired" and each of the xylem layers start to work when new foliage develops? Measurements of sap flow radial patterns using sensors left in a tree stem after severing for prolonged periods (several growing seasons) might show this. One example of such studies, carried out with a lime tree, will be presented in a future paper.

We did not show any material here on interactions between conducting "closed" pipe units (horizontal radial and tangential transport) according to changes in driving forces. A combination of measurements of sap flow in different xylem layers with studies of vulnerability to cavitation and/or gradients of water potential in different parts of the canopy could be very useful for future studies of this type. Measurements of changes in radial patterns of sap flow in different tree parts during non-destructive experiments (such as localized irrigation of dry soil or localized fertilization, misting or shading of branches), allowing work with "closed" pipes, could provide an improved means for studying such "difficult" components 

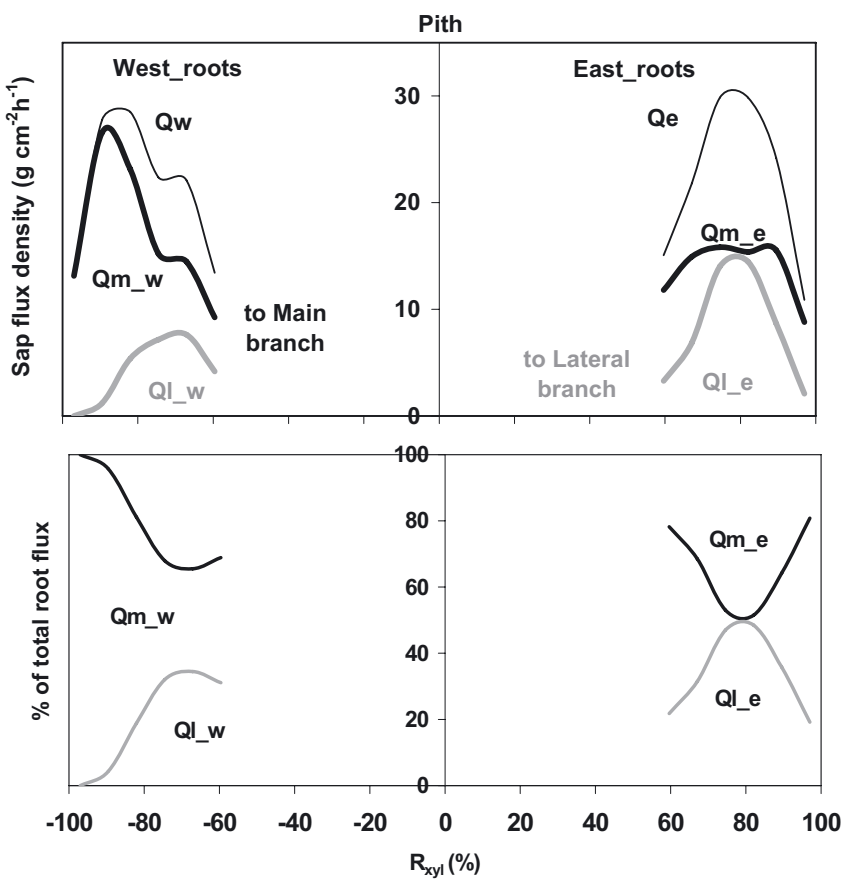

Figure 6. Radial patterns of sap flux densities at the western (left) and the eastern (right) sides of the maple stem demonstrating water portioning from the corresponding root sectors (black thin lines) to the main (black thick lines) and the lateral (grey thick lines) branches. $R_{\text {xyl }}$ means stem radius in a measured place without bark thickness. Upper panels show absolute values of SFD, lower panels represent their percentage from the total root flux for each root sector.

of water transport as radial and tangential fluxes. Most probably, horizontal transport should be connected with integration through intervessel pits and maybe considered as (1) a means for flow redistribution between stem xylem layers occurring in daily circles of transpiration and tissue refilling at night; and as (2) a tree safety feature under extremes.

Both proposed hypotheses were confirmed by this work: our experimental maple trees had an integrated topology with independent pipes sharing space in the stem xylem at both tree sides for water pathways connecting opposite roots with both branches. The integration of axial transport in the stem xylem presumably occurred through the cross-grained network of axial vessels. The stem xylem (as an integrating place for water pathways) redistributed flows from the corresponding root sector between different canopy parts so that they were not competing. Part of the vascular system in the stem became unused after removing a certain part of the canopy, increasing the asymmetry of functional stem architecture without providing a benefit for the remaining foliage.

From the methodological point of view, this experiment had several important consequences: (1) connections of any part of the crown with the stem xylem are detectable through sap flow measurements along the stem radius; (2) short-term successive cuts at midday (preferably during stable, sunny weather) could be applied for studies of water pathways to different parts of

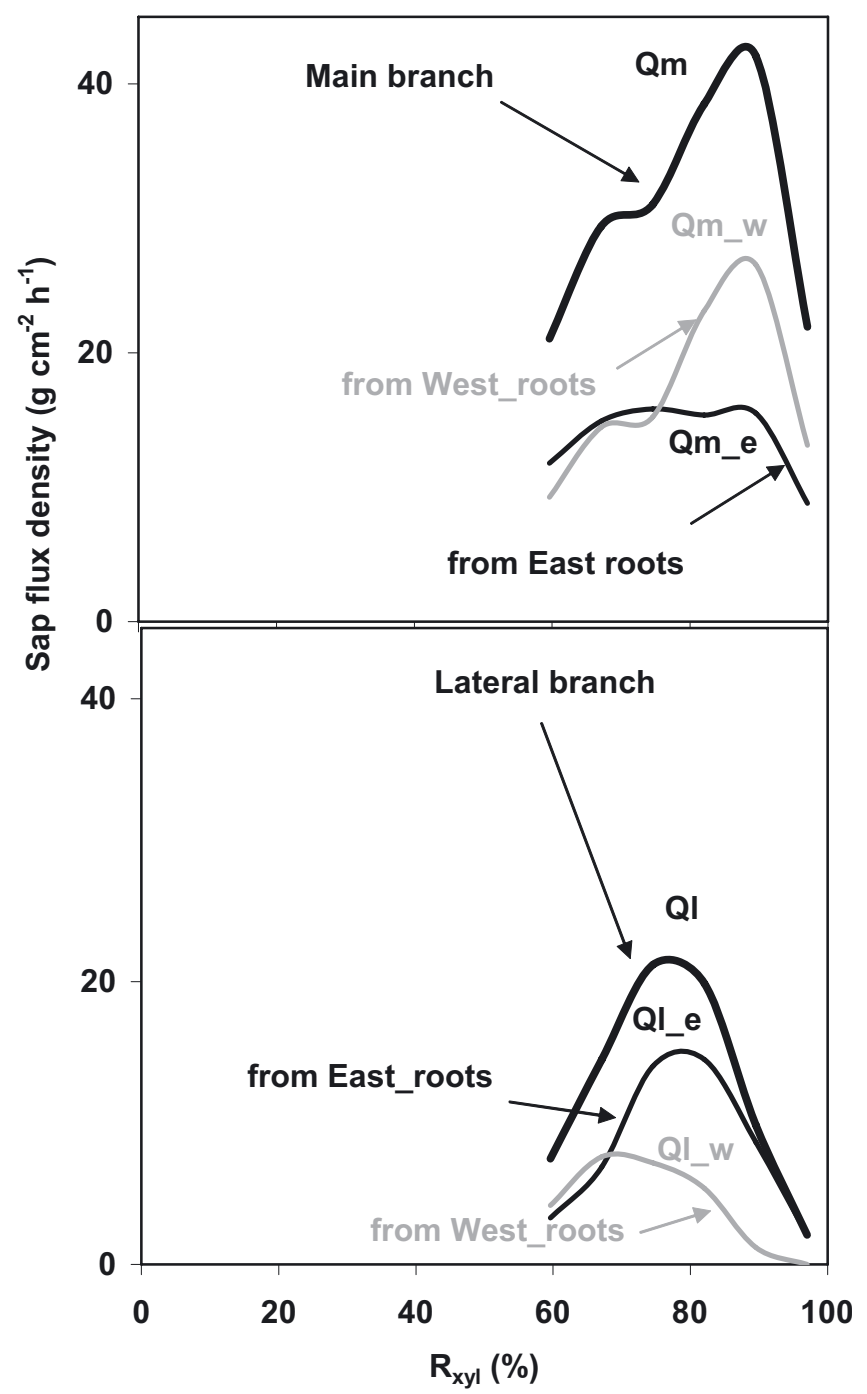

Figure 7. Radial patterns of sap flux densities, demonstrating summarized flow profiles (black thick lines) to the main (upper panel) and the lateral (lower panel) branches. Each summarized profile was composed from two separate profiles demonstrating portions of water moving from the opposite root sectors (east-black and west-grey thin lines). $R_{\mathrm{xyl}}$ means stem radius in a measured place without bark thickness.

the same branch through the stem xylem; and (3) measurements of sap flow on one side of a stem when studying sap flow responses to branch severing is not enough: one can obtain very different responses depending on the chosen side.

Acknowledgements: This work was partially supported by the Czech national project MSM 6215648902. The author thanks Amy Zanne and Pierre Cruiziat for their critical comments on early drafts of the manuscript and Hanno Richter for valuable help with its later versions. The author also thanks Valeriy Nadezhdin for his important field support. 
A

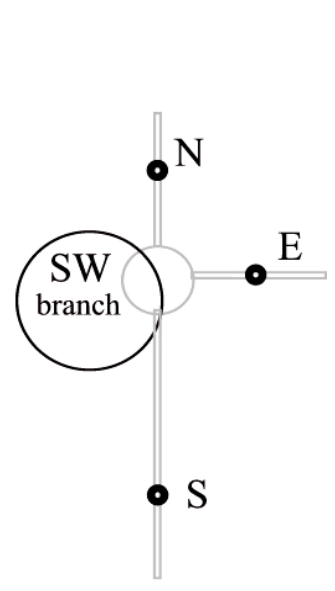

B

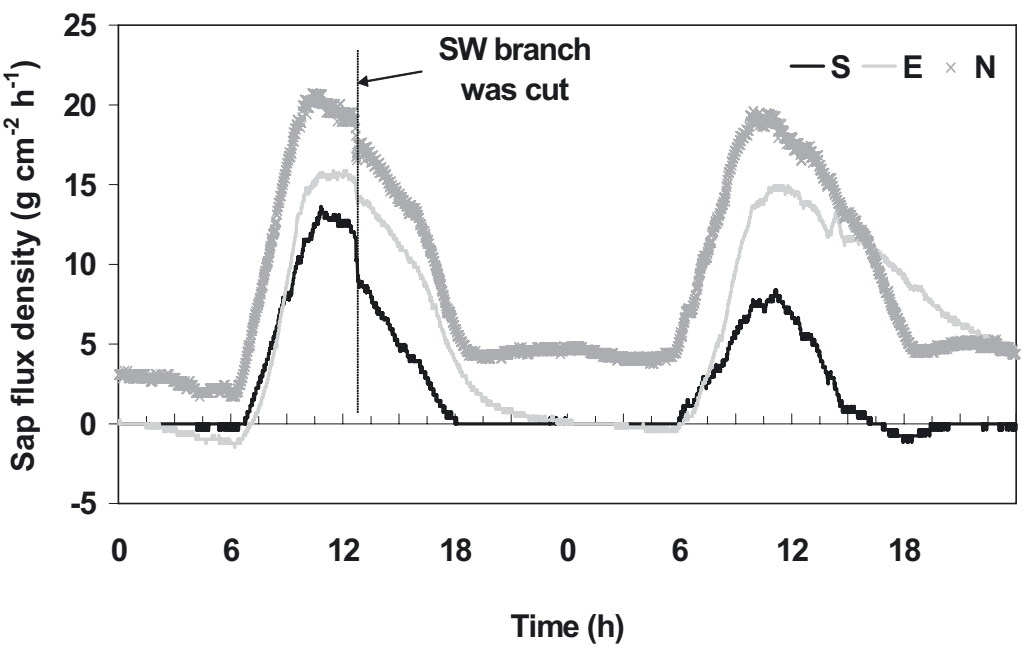

Figure 8. (A): Scheme of the cut branch (Exp. 2) and positioning of the single HFD sensors on three small superficial roots of the second sample maple. Sap flow dynamics (B) in the measured roots during day of branch severing and on the following day. Vertical line indicates the moment of cutting the SW branch.

\section{REFERENCES}

Alarcon J.J., Domingo R., Green S.R., Nicolas E., and Torrecillas A., 2003. Estimation of hydraulic conductance within field-grown apricot using sap flow measurements. Plant Soil 251: 125-135.

Boyer J.S., 1985. Water transport. Ann. Rev. Plant Physiol. 36: 473-516.

Brooks J.R., Schulte P.J., Bond B.J., Coulombe R., Domec J.C., Hinckley T.M., McDowell N., and Phillips N., 2003. Does foliage on the same branch compete for the same water? Experiments on Douglas-fir trees. Trees 17: 101-108.

Cermak J. and Kucera J., 1990. Water uptake in healthy and ill trees under drought and hypoxia and non-invasive assessment of the effective size of root systems. In: Persson H. (Ed.), Proc. COST 612 Workshop "Above and belowground interactions in forest trees in acidified soils", Simlangsdalen, Sweden, pp. 185-195.

Cruiziat P., Cochard H., and Ameglio T., 2002. Hydraulic architecture of trees: main concepts and results. Ann. For. Sci. 59: 723-752.

Hubbard R.M., Bond B.J., and Ryan M.G., 1999. Evidence that hydraulic conductance limits photosynthesis in old Pinus ponderosa trees. Tree Physiol. 19: 165-172.

Huber B., 1928. Weitere quantitative Untersuchungen uber das Wasserleitungssystem der pflanzen. Jahrsblad des Wissenschaftliche Botany 67: 877-959.

Infante J.M., Mauchamp A., Fernandez-Ales R., Joffre R., and Rambal S., 2001. Within-tree variation in transpiration in isolated evergreen oak trees: evidence in support of the pipe model theory. Tree Physiol. 21: 409-414.

Fujii T., Lee S.J., Kuroda N., and Suzuki Y., 2001. Conductive function of intervessel pits through a growth ring boundary of Machilus thunbergii. IAWA J. 22: 1-14.

Kaipiainen L.K. and Hari P., 1985. Balance of water transport system in Pinus sylvestris. I. Pathways of water in xylem (in Russ.). Lesovedenije 5: 23-28.

Kaipiainen L.K. and Sofronova G.I., 2003. The role of the transport system in the control of the source-sink relations in Pinus sylvestris. Russ. J. Plant Physiol. 50: 125-132.

Kitin P.B., Fujii T., Abe H., and Funada R., 2004. Anatomy of the vessel network within and between tree rings of Fraxinus Lanuginosa (Oleaceae). Amer. J. Bot. 91: 779-788.
Kurth W. and Lanwert D., 1995. Biometrical foundation for a dynamical architectural model of spruce (Picea-abies (L) karst). Allg. Forst Jagdztg. 166: 177-184.

Lanner R.M., 2002. Why do trees live so long? Ageing Res. Rev. 1: 653671.

Larson D.W., Doubt J., and Matthes-Sears U., 1994. Radially sectored hydraulic pathways in the xylem of Thuja occidentalis as revealed by use of dyes. Int. J. Plant Sci. 155: 569-582.

Loepfe L., Martinez-Vilalta J., Pinol J., and Mencuccini, M., 2007. The relevance of xylem network structure for plant hydraulic efficiency and safety. J. Theor. Biol. 247: 788-803.

Luttschwager D. and Remus R., 2007. Radial distribution of sap flux density in trunks of a mature beech stand. Ann. For. Sci. 64: 431-438.

MacKay J.F.G. and Weatherley P.E., 1973. The effects of transverse cuts through the stems of transpiring woody plants on water transport and stress in the leaves. J. Exp. Bot. 24: 15-28.

Matthes U., Kelly P.E., Ryan C.E., and Larson D.W., 2002. The formation and possible ecological function of stem strips in Thuja occidentalis. Intern. J. Plant Sci. 163: 949-958.

Nadezhdina N. and Cermak J., 2000a. Responses of sap flow rate along tree stem and coarse root radii to changes of water supply. In: Stokes A. (Ed.), The Supporting roots of trees and woody plants: form, function and physiology, Developments in Plant and Soil Sciences, Vol. 87, Kluwer Academic Publishers, 227-238.

Nadezhdina N. and Cermak J., 2000b. Responses of sap flow in spruce roots to mechanical injury. In: Klimo E., Hager H., and Kulhavy J. (Eds.), Spruce Monocultures in Central Europe: Problems and Prospects. EFI Proc. 33: 167-175.

Nadezhdina N. and Cermak J., 2003. Instrumental methods for studies of structure and function of root systems in large trees. J. Exp. Bot. 54: $1511-1521$.

Nadezhdina N., Cermak J., and Nadezhdin V., 1998. Heat field deformation method for sap flow measurements. In: Cermak J. and Nadezhdina N. (Eds.), Measuring sap flow in intact plants. Proc. 4th. International Workshop, Zidlochovice, Czech Republic, IUFRO Publications, Brno, Czech Republic: Publishing House of Mendel University, pp. 72-92.

Nadezhdina N., Cermak J., Morales D., Jimenez M.S., Raschi A., Tognetti R., and Ferreira M.I., 2001. Variations in conducting 
patterns of trees growing in three Mediterranean countries and relations to crown development. In: Radoglou K. (Ed.), Forest Research: a challenge for an integrated European approach. Proc. International Conference, Thessaloniki, Greece, pp. 507-512.

Nadezhdina N., Cermak J., and Ceulemans R., 2002. Radial patterns of sap flow in woody stems of dominant and understory species: scaling errors associated with positioning of sensors. Tree Physiol. 22: 907918.

Nadezhdina N., Tributsch H., and Cermak J., 2004. Infra-red images of heat field around a linear heater and sap flow in stems of lime trees under natural and experimental conditions. Ann. For. Sci. 61: 203213.

Nadezhdina N., Ferreira M.I., Silva R., and Pacheco C.A., 2008. Seasonal variation of water uptake of a Quercus suber tree in Central Portugal. Plant Soil 305: 105-119.

Orians C.M. and Jones C.G., 2001. Plants as resource mosaics: a functional model for predicting patterns of within-plant resource heterogeneity to consumers based on vascular architecture and local environmental variability. OIKOS 94: 493-504.

Orians C.M., Van Vuuren M.M.I., Harris N.L., Babst B.A., and Ellmore G.S., 2004. Differential sectoriality in long-distance transport in temperate tree species: evidence from dye flow, N-15 transport, and vessel element pitting. Trees 18: 501-509.

Orians C.M., Babst B., and Zanne A.E., 2005. Vascular Constraints and Long-Distance Transport in Dicots. In: Holbrook N.M. and Zwieniecki M. (Eds.), Vascular transport in plants. Oxford, Elsevier/AP co-imprint, pp. 355-371.

Pataki D.E., Oren R., and Phillips N., 1998. Responses of sup flux and stomatal conductance of Pinus taeda L. trees to stepwise reduction in leaf area. J. Exp. Bot. 49: 871-878.

Pepin S., Livingston N.J., and Whitehead D., 2002. Responses of transpiration and photosynthesis to reversible changes in photosynthetic foliage area in western red cedar (Thuja plicata) seedlings. Tree Physiol. 22: 363-371.

Roach W.A., 1939. Plant injection as a physiological method. Ann. Bot. 3: $155-226$.

Saveyn A., Steppe K., and Lemeur R., 2008. Spatial variability of xylem sap flow in mature beech (Fagus sylvatica) and its diurnal dynamics in relation to microclimate. Botany 86: 1440-1448.

Schulte P.J. and Brooks J.R., 2003. Branch junctions and the flow of water through xylem in Douglas-fir and ponderosa pine stems. J. Exp. Bot. 54: 1597-1605.

Shinozaki K., Yoda K., Hozumi K., and Kira T., 1964a. A quantitative analysis of plant form - the pipe model theory. I. Basic analysis. Jpn. J. Ecol. 14: 97-105.
Shinozaki K., Yoda K., Hozumi K., and Kira T., 1964b. A quantitative analysis of plant form - the pipe model theory. II. Further evidence of the theory and its application in forest ecology. Jpn. J. Ecol. 14: 133-139.

Steppe K., Cnudde V., Girard C., Lemeur R., Cnudde J.P., and Jacobs P., 2004. Use of X-Ray Computed Microtomography for Non-Invasive Determination of Wood Anatomical Characteristics. J. Struct. Biol. 148: 11-21.

Stokes A., Berthier S., Nadezhdina N., Cermak J., and Loustau D., 2000. Sap flow in trees in influenced by stem movement. In: Spatz HCh. and Speck T. (Eds.), Proc. 3rd Plant Biomechanics Conf. Freiburg-Badenweiler, Aug. 27-Sept. 2, 2000. Georg Thieme Verlag, Stuttgart, New York, pp. 272-277.

Tyree M.T. and Ewers F.W., 1991. The hydraulic architecture of trees and other woody plants. New Phytol. 119: 345-360.

Van den Honert T.H., 1948. Water transport in plants as a catenary process. Disc Faraday Soc. 3: 146-153.

Vasicek F., 1984. The characteristics of biogenocenoses. In: Vasicek F. (Ed.), Ecophysiological and ecomorphological studies of individual trees in the spruce ecosystem of the Drahanska Vrchovina uplands (Czechoslovakia). Folia Universitatis Agriculturae, Agr. Univ. Brno.

Vite J.P. and Rudinsky J.A., 1959. The water conducting systems in conifers and their importance to the distribution of trunk-injected chemicals. Contribution of Boyce Thompson Institute 20: 27-38.

Waring R.H., Gholz H.L., Grier C.C., and Plummer M.L., 1977. Evaluating stem conducting tissue as an estimator of leaf area in four woody angiosperms. Can. J. Bot. 55: 1474-1477.

Watson M.A. and Casper B.B., 1984. Morphogenetic constraints on patterns of carbon distribution in plants. Ann. Rev. Ecol. Syst. 15: 233258.

West G.B., Brown J.H., and Enquist B.J., 1999. A general model for the structure and allometry of plant vascular systems. Nature 400: 664667.

Whitehead D., Livingston N.J., Kelliher F.M., Hogan K.P., Pepin S., McSeveny T.M., and Byers J.N., 1996. Response of transpiration and photosynthesis to a transient change in illuminated foliage area for a Pinus radiata D. tree. Plant Cell Environ. 19: 949-957.

Wullschleger S.D. and King A.W., 2000. Radial variation in sap velocity as a function of stem diameter and sapwood thickness in yellowpoplar trees. Tree Physiol. 20: 511-518.

Zanne A.E., Sweeney K., Sharma M., and Orians C.M., 2006. Patterns and consequences of differential vascular sectoriality in 18 temperate tree and shrub species. Funct. Ecol. 20: 200-206.

Zimmermann M.H., 1983. Xylem structure and the ascent of sap. Springer Verlag, Berlin. 